\title{
Estrés celular y SARS-CoV-2.
}

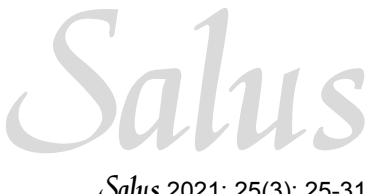

Cellular stress and SARS-CoV-2.

https://doi.org/10.54139/salus.v25i3.129

\begin{abstract}
Mariangel Delgado 1 (D) Mariajose Rodríguez ${ }^{2}$ (ID) Zoila Moros ${ }^{3}$ (I) Olga Carolina Aristimuño (D) Christopher Franco ${ }^{3}$ (D) Esmeralda Vizzi ${ }^{3}$ (D) Ferdinando Liprandi ${ }^{3}$, Mariana Hidalgo (D) Domingo J Garzaro ${ }^{2}$ (D) Héctor R Rangel ${ }^{2}$ (D) Carmen L

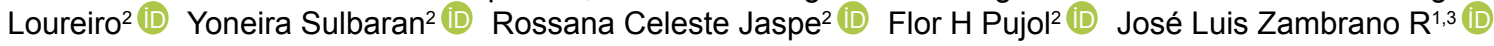

\section{RESUMEN}

Introducción: El agente etiológico responsable de COVID-19, SARSCoV-2, es un virus ARN perteneciente a la familia Coronaviridae. Durante la replicación, los componentes virales interactúan con la maquinaria celular induciendo alteraciones en la fisiología celular, lo que contribuye a la patogénesis del virus. Método: Revisión bibliográfica en NCBI/Pubmed sobre estrés celular y SARS-CoV-2 Hallazgos de interpretación: Como respuesta a la infección, en la célula hospedadora se activan vías de señalización, cuyo principal objetivo es recuperar la homeostasis y de no lograrlo, inducir a la activación de la muerte celular. Entre las vías de señalización mejor caracterizadas, destacan las rutas de estrés celular como el estrés oxidativo, la UPR (Respuesta a proteínas no plegadas), y la autofagia, las cuales son evolutivamente bien conservadas y además están interconectadas entre sí. Hay fuerte evidencia teórica y experimental de diversas interacciones de algunos componentes de estas rutas con distintas proteínas virales de los coronavirus, y ya se han adelantado algunos estudios con SARS-CoV-2. En esta revisión, resaltamos algunas de las rutas celulares-virus que se han caracterizado hasta el momento.

Reflexiones finales: Aún queda mucho por entender de estas rutas y su relación con las infecciones virales; esto pudiera constituir un importante blanco para la investigación y desarrollo de terapias antivirales.

Palabras Clave: SARS-CoV-2, COVID-19, estrés celular, UPR, estrés oxidativo, autofagia

${ }^{1}$ Unidad de Microscopía electrónica y confocal del Centro de Microbiología y Biología Celular, Instituto Venezolano de Investigaciones Científicas (IVIC), Caracas, Miranda, Venezuela.

${ }^{2}$ Laboratorio de Virología Molecular, Centro de Microbiología y Biología Celular, Instituto Venezolano de Investigaciones Científicas, Caracas, Miranda, Venezuela.

${ }^{3}$ Laboratorio de Biología de Virus del Centro de Microbiología y Biología Celular, Instituto Venezolano de Investigaciones Científicas (IVIC), Caracas, Miranda, Venezuela.

${ }^{4}$ Laboratorio de Inmunoparasitología del Centro de Microbiología y Biología Celular, Instituto Venezolano de Investigaciones Científicas (IVIC), Caracas, Miranda, Venezuela.

Autor de correspondencia: José Luis Zambrano R (D)

E-mail: jlzr@ivic.gob.ve_jlzr.ivic@gmail.com

Recibido: 09-11-2021

Aprobado: 03-12-2021

\section{ABSTRACT}

Background: SARS-CoV-2, the etiological agent responsible for COVID-19, is an RNA virus belonging to the Coronaviridae family. During the virus replication, viral components interact with the cellular machinery, inducing alterations in cell physiology, which contributes to viral pathogenesis. Methods: A bibliographical research about cellular stress and SARS-CoV-2 was performed at NCBI/Pubmed. Results: In response to the infection, signaling pathways are activated in the host cell, the goal of these pathways being to restore homeostasis. If homeostasis is not recovered, the signaling leads to cell death activation. Among the best-characterized signaling pathways, the cellular stress pathways such as oxidative stress, UPR, and autophagy stand out, which are evolutionarily conserved and are also interconnected with each other. There is strong theoretical and experimental evidence of various interactions of some components of these pathways with different viral proteins of coronavirus, and some studies with SARS-CoV-2 have already been performed. In this review, we highlight some of the cellular pathways-virus characterized to date. Conclusions: The cellular pathways and their relationship to viral infections remains unclear. The study of these relationships might constitute an important target for new research and the development of antiviral therapies.

Keywords: SARS-CoV-2, COVID-19, cellular stress, UPR, oxidative stress, autophagy.

\section{INTRODUCCIÓN}

Luego de la aparición de SARS (2002) y MERS (2012), a finales de 2019 se detectó en Wuhan la tercera enfermedad infecciosa por coronavirus (CoV) humano, altamente patogénico de este siglo, COVID-19. Está caracterizada por su alta tasa de infección, representando una fuerte amenaza para la salud global (1). SARS-CoV-2, el agente etiológico identificado, es un virus con envoltura con un genoma de ARN monocatenario de polaridad positiva, y está compuesto por cuatro proteínas estructurales y 16 proteínas no estructurales (NSP). Éstas últimas son elementos críticos para el establecimiento del complejo de replicación y transcripción (RTC) $(2,3)$, y median el secuestro de la membrana del retículo endoplásmico (RE) promoviendo la inducción del estrés en el RE (4).

Generalmente durante el transcurso de una infección por CoV se sintetizan proteínas en grandes cantidades a nivel del RE y estos eventos se convierten en un estímulo lo suficientemente fuerte para perturbar la homeostasis del 
RE. Se generan proteínas mal plegadas, ya sea por estar defectuosas, o porque se producen más rápido de lo que el sistema puede plegar y modificar correctamente (5-7). Las células activan mecanismos de adaptación y supervivencia que se conocen en conjunto como la vía de la respuesta de proteínas no plegadas (UPR, por sus siglas en inglés), la cual es una compleja cascada de transducción de señales que llevan a sobre-expresar chaperonas y otros factores involucrados en la degradación de proteínas, así como a disminuir considerablemente la síntesis de proteínas para detener su acumulación.

Se han descrito diversos mecanismos de control de la UPR empleados por los virus, enfocándose en suprimir los aspectos deletéreos y mantener aquellos aspectos que son favorables a su replicación (8). De no lograrse la restitución de la homeóstasis, se inician programas celulares que conducen a la muerte celular $(9,10)$. La UPR y la autofagia están interconectadas y se ha descrito que la inducción de la UPR podría potencialmente facilitar o promover la autofagia $(11,12)$. Estudios previos, han demostrado que los CoV también inducen autofagia y, por lo tanto, es probable que durante la infección por SARS-CoV-2 se lleven a cabo procesos de autofagia, ya sea, por interacción directa o a través de la inducción de UPR (13-15).

Durante las primeras etapas de interacción célula-SARSCoV-2, el virus ingresa a las células hospedadoras por interacción del receptor de la enzima convertidora de angiotensina 2 (ACE2), y la proteína $S$ (espiga) viral es cebada por la serina proteasa 2 transmembrana (TMPRSS2) $(3,4)$. En condiciones fisiológicas normales, ACE2 actúa convirtiendo a la angiotensina 2 en angiotensina 1, lo que conduce a la producción de ATP y la producción de ROS mediada por NADPH oxidasa 4 (NOX4) $(15,16)$. Por ello, se ha propuesto una relación entre la infección con SARSCoV-2 y el estrés oxidativo (17).

Si bien ya se conoce la estrategia básica de replicación viral de SARS-CoV-2, se desconoce aún gran parte de la interacción virus-hospedero. La presente revision trata de exponer la evidencia existente hasta el momento de la interacción del virus y los diferentes mecanismos de estrés celular.

Hallazgos de interpretación. Biología del SARS-CoV-2 Los CoV pertenecen al orden Nidovirales, familia Coronaviridae, nombre asignado porque morfológicamente presentan espigas "en forma de corona" sobre la membrana externa de los viriones, que son visibles por microscopía electrónica. Presentan un genoma ARN de sentido positivo, monocatenario y con una envoltura grande. Se dividen en cuatro géneros: Alfa, Beta, Gamma y Deltacoronavirus, siendo hasta el momento virus de los géneros Alfa y Beta, los responsables de infecciones en humanos $(3,18)$.

El SARS-CoV-2 pertenece al género Betacoronavirus. Posee un genoma de aproximadamente $30 \mathrm{~kb}$, que codifica
14 marcos de lectura abiertos (ORFs). Como en todos los miembros del orden Nidovirales, se ha descrito que tiene una organización genómica altamente conservada, con una ARN polimerasa con alta capacidad correctora y expresa genes no estructurales por cambio de marco ribosómico $(18,19)$.

Una vez que la proteína $S$ interactúa con el receptor ACE2 (Figura 1), en colaboración con la serina proteasa de superficie celular TMPRSS2, ingresa a la célula por un mecanismo de endocitosis, liberándose el material genético por fusión de la vesícula con lisosomas o mediante fusión con un endosoma temprano $(18,20)$.

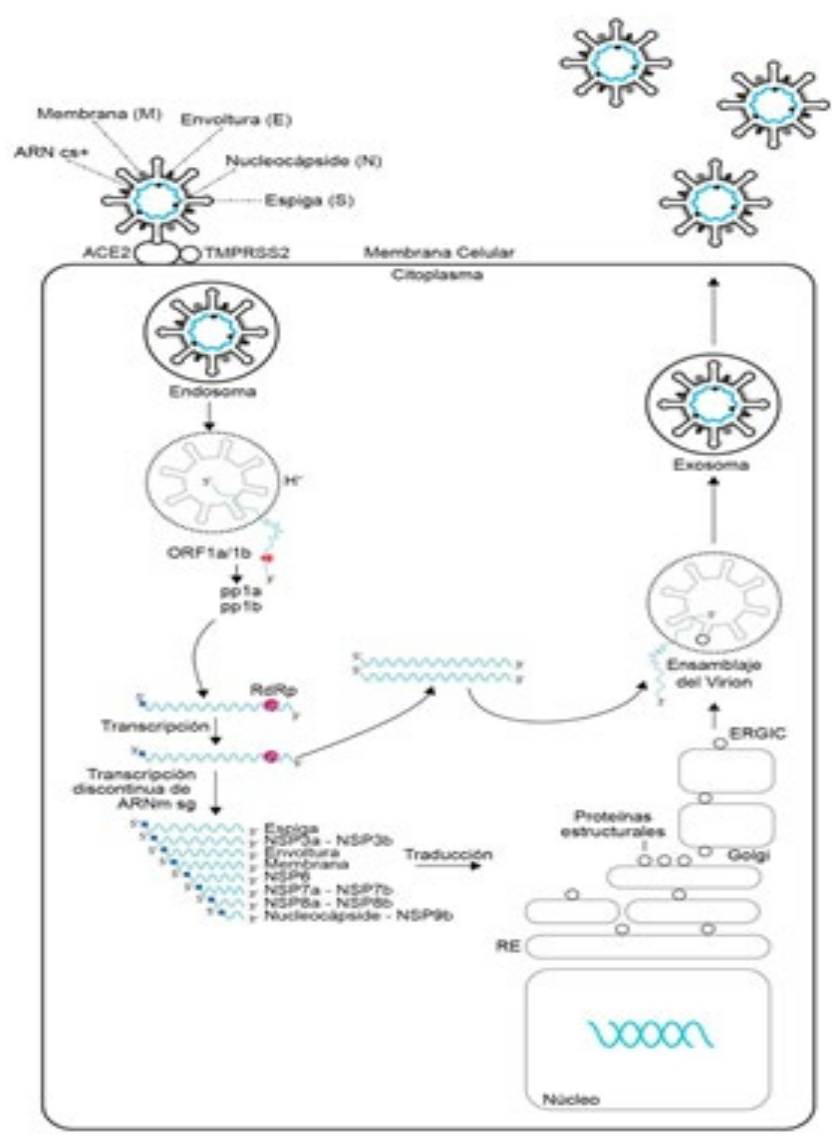

Figura 1. Replicación del SARS.Cov-2. EI SARS-CoV-2 se une a factores de unión celular y la interacción de la proteína de la espiga (S) con el receptor celular la enzima convertidora de angiotensina 2 (ACE2), junto con la serina proteasa de superficie celular TMPRSS2, que promueven la absorción por endocitosis. Después de la entrada de la partícula del SARS-CoV-2 por vía endosomal, la partícula pierde la cápside y la liberación del ARN genómico conlleva a la traducción inmediata de dos grandes marcos de lectura abiertos, ORF1a y ORF1b por la ARN polimerasa dependiente de ARN (RdRp). Las poliproteínas pp1a y pp1b resultantes se procesan co-traduccionalmente y post-traduccionalmente en las NSPs que forman el complejo de replicación y transcripción viral. La replicación del ARN genómico y la transcripción de ARNm subgenómicos (ARNm sg) se producen por transcripción discontinua, donde todos los ARNm poseen la secuencia líder en el extremo $5^{\prime}$. Las proteínas estructurales traducidas se trasladan a las membranas del retículo endoplásmico (RE) y transitan a través del compartimento intermedio del RE al Golgi (ERGIC), donde se liberan de la célula infectada por exocitosis. Zambrano R. J 2021. 
El ARN genómico en el citoplasma de la célula huésped es traducido en su ORF1 para producir la polimerasa viral, la cual se va a encargar, por transcripción discontinua, de generar los ARN mensajeros subgenómicos (sgRNAm). Las proteínas estructurales $S, E, M$, traducidas a partir de los sgRNAm, se trasladan a las membranas del RE y transitan a través del compartimento intermedio del RE al Golgi (ERGIC), donde la interacción con el ARN genómico recién producido encapsulado en $\mathrm{N}$ da como resultado la gemación en la luz de los compartimentos vesiculares secretores. Finalmente, los viriones se secretan de la célula infectada por exocitosis $(18,21,22)$.

El genoma también es sometido a traducción inmediata de dos marcos de lecturas abiertos, ORF1a y ORF1b. Las poliproteínas pp1a y pp1ab resultantes se procesan cotraduccionalmente y postraduccionalmente en las proteínas no estructurales individuales NSP1-NSP11, que forman el complejo de replicación y transcripción viral. La interacción de las proteínas no estructurales con la maquinaria celular permite la biogénesis de orgánulos de replicación virales que consta de vesículas de doble membrana (DMV), membranas contorneadas (CM) y pequeñas esférulas abiertas de doble membrana (DMS) (21). En total, el genoma del SARS-CoV-2 codifica cuatro proteínas estructurales y dieciséis proteínas no estructurales, y se ha descrito que algunas de estas proteínas interactúan con las rutas de estrés celular, bien sean en la activación o modulación de las mismas.

Estrés oxidativo y SARS-CoV-2. El estrés oxidativo se ha definido como el resultado de un desequilibrio del sistema oxidativo intracelular, que consiste principalmente en radicales libres, especies reactivas de oxígeno (ROS), especies reactivas de nitrógeno (RNS), y sistemas antioxidantes que neutralizan estos radicales libres conduciendo al daño celular (23).

El sistema oxidante consiste de subproductos del metabolismo aeróbico en varios orgánulos celulares, incluidas las mitocondrias y el RE, y funcionan como moduladores de numerosos procesos fisiológicos normales. Cuando los mecanismos que contrarrestan este sistema fallan, se induce el estrés oxidativo y eso conlleva a trastornos fisiológicos celulares como disfunción metabólica y activación de la respuesta inflamatoria. El estrés oxidativo ha sido descrito en determinadas patologías crónicas como hipertensión, diabetes mellitus, cáncer, enfermedad coronaria, enfermedad crónica renal, entre otras (24-26). Se ha estudiado que algunas infecciones virales, especialmente las causadas por virus ARN, inducen la producción desregulada de ROS, lo que lleva al reclutamiento de células inflamatorias en el sitio de la infección, inducción de la muerte celular y la liberación de viriones, contribuyendo a la patogénesis viral $(25,27,28)$.

El estrés oxidativo, al promover la inflamación, es un activador de la respuesta inmunitaria antiviral, y cuando ésta es desproporcionada, provoca una tormenta de citocinas e inflamación grave, perjudicial para tejidos y órganos diana de la infección $(25,29)$. En los casos sintomáticos de pacientes con COVID-19 se han encontrado efectos de la activación desproporcionada del sistema inmunitario, con inflamación y en los casos más graves, con tormentas de citocinas. Esto indicaría que el virus SARS-CoV-2, al igual que otros virus ARN tendría la capacidad de desencadenar estrés oxidativo.

Del receptor ACE2 y su implicación en la producción de ROS se ha demostrado que la proteasa viral 3CLpro de SARS-CoV aumenta significativamente los niveles de ROS y la activación del gen NF-kB en ensayos in vitro (Figura 2A) (30-33).

Estudios bioinformáticos han establecido que hay dominios funcionales conservados en la proteína 3 a de los virus SARSCoV y SARS-CoV-2, y que estos dominios conservados pudieran ser los responsables de la activación de NF-kB durante el desarrollo de COVID-19, aunque estos estudios todavía requieren de confirmación experimental (34). Se conoce que el factor de transcripción NF-kB se produce como respuesta inicial al estrés oxidativo. Sin embargo, durante el estrés oxidativo sostenido disminuye la actividad de este factor de transcripción y se promueve la apoptosis (35). Por ello, se propone que la activación del factor por NF-kB, sea un mecanismo de defensa viral para evitar la apoptosis.

Las proteínas $3 a$ y $\mathrm{N}$ de SARS-CoV también se han asociado con la activación de las vías de muerte de las células mediadas por mitocondrias, descubriéndose que la proteína 3a lo hace a través de la vía p38 $\operatorname{MAPK}(33,36,37)$. Además, se han detectado formas activadas de todos los miembros de MAPK en células infectadas con SARS-CoV, y la activación de esta vía es necesaria para incrementar la producción de citocinas proinflamatorias, como IL-6, TNF- $\alpha$ e IL-1 $\beta$, presentes en la tormenta de citocinas producida por el SARS-CoV-2 $(33,38)$.

Estrés del retículo endoplasmático y SARS-CoV-2. Hasta ahora se conoce que los CoV producen estrés en RE de tres maneras: 1. Formando vesículas de doble membrana (DMV); 2. Por la glicosilación de proteínas virales; y 3. Agotando los lípidos de la membrana del RE (39). A excepción de la proteína $\mathrm{N}$, todas las proteínas estructurales del CoV son proteínas transmembrana sintetizadas en el RE. Proteínas chaperonas como la calnexina, y las proteínas de choque térmico (HSP), interactúan con los polipéptidos virales recién sintetizados en RE para garantizar el plegamiento adecuado de las proteínas $(40,41)$.

Para ello se induce el reordenamiento masivo del orgánulo y se forman las DMV $(21,42)$. Posteriormente, las proteínas virales aún inmaduras se transportan a ERGIC, donde las partículas virales estructurales se ensamblan para formar la estructura viral (18). Además hay que considerar la gemación de CoV, que después de múltiples replicaciones conduce a su liberación del RE al compartimento intermedio de Golgi (ERGIC) de la célula huésped. La gemación da como resultado el agotamiento de los lípidos de la membrana del RE, afecta la integridad del RE y, por lo tanto, aumenta el estrés del RE $(42,43)$. 


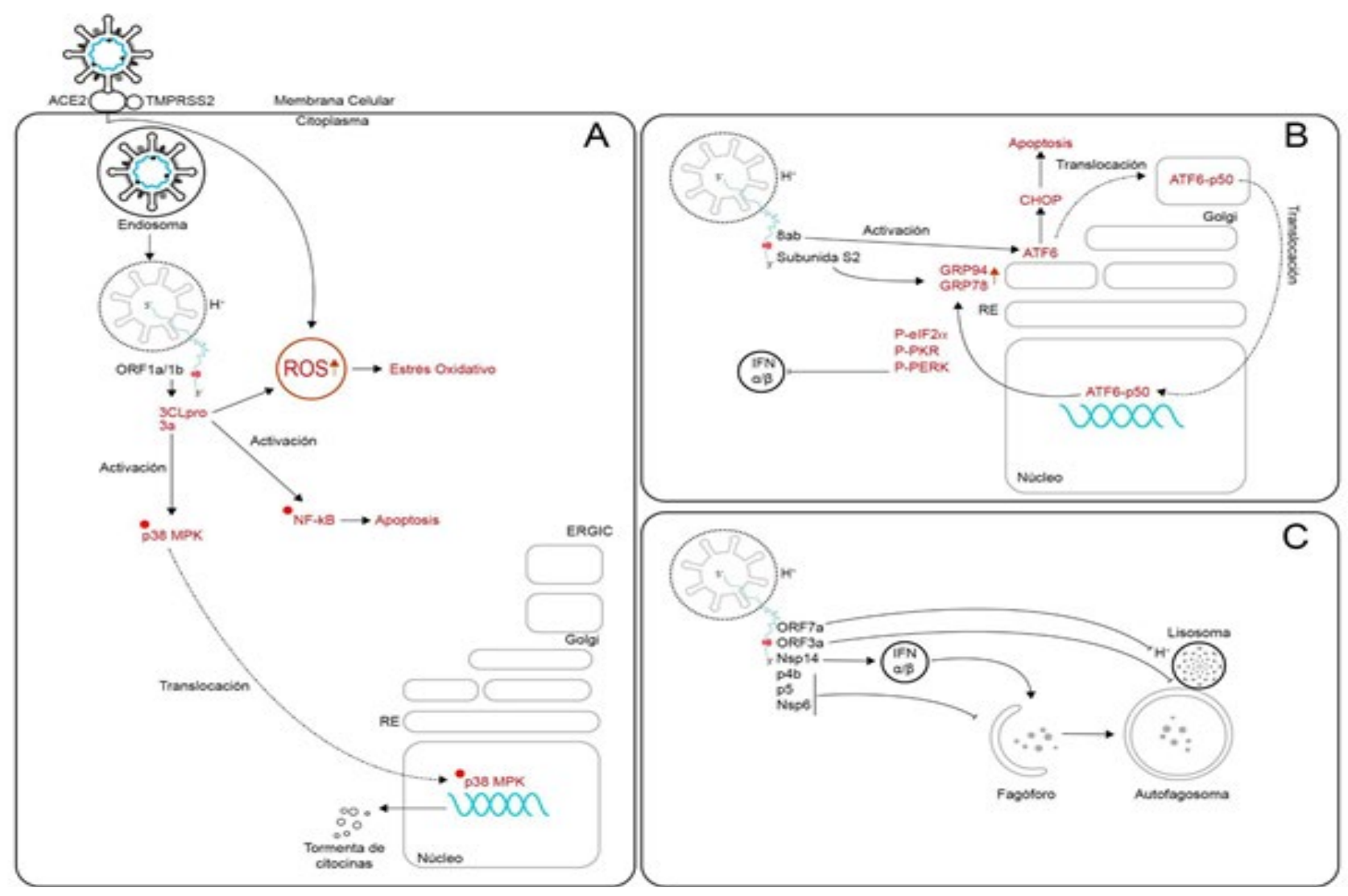

Figura 2. Estrés celular y SARS-CoV-2. 2A. Estrés Oxidativo y SARS.CoV-2. El receptor ACE2 está involucrado en la activación de ROS. La proteasa viral 3CLpro aumenta significativamente niveles de ROS y la activación del gen NF-kB. Los dominios funcionales de la proteína pudieran ser los responsables de la activación de NF-kB y promueve la apoptosis. Las proteínas 3a y N se han asociado con la activación de las vías de muerte celular a través de la vía p38 MAPK y la activación de esta vía es necesaria para incrementar la producción de citocinas proinflamatorias, como IL-6, TNF- $\alpha$ e IL-1 $\beta$ presentes en la tormenta de citocinas. 2B. UPR y SARS-CoV-2. La sobre-expresión de la subunidad S2 incrementa los niveles de expresión del gen GRP94 y GRP78. Las células infectadas SARS-CoV presentan una significativa fosforilación de elF2a, PKR y PERK. PERK suprime la señalización del interferón tipo I. ATF6, La proteína accesoria de 8ab y la proteína ORF8 de SARS-CoV-2 inducen la proteólisis de ATF6. P50 se transloca al núcleo y promueve la síntesis de chaperonas del RE, como GRP78 y GRP94. ATF6 promueve a la apoptosis, por la activación de CHOP y la supresión de Mcl-1. 2C. Autofagia y SARSCoV-2. La autofagia se inicia mediante la formación del fagóforo que envuelve al material que será degradado y los secuestra dentro de un autofagosoma. El autofagosoma maduro se fusiona con un lisosoma. Las proteínas Nsp6, p4b y p5 pueden limitar la actividad de los autofagosomas. La Nsp14 favorece la degradación lisosomal del IFN tipo I, y ORF3a previene la fusión autofagosoma-lisosoma y ORF7a interfiere con la acidificación del autofagosoma que logra fusionarse al lisosoma. Zambrano R. J 2021.

Como respuesta a estas constantes demandas de producción viral, se activa una vía de señalización de compensación: la respuesta de la proteína desplegada (UPR). La UPR tiene la capacidad de promover la supervivencia celular al aumentar las membranas del RE y la capacidad de plegamiento, pero también tiene la capacidad de inducir la muerte celular si el estrés es persistente. Además, la UPR se asocia con varias actividades celulares importantes que incluyen apoptosis, angiogénesis, autofagia, rutas de la proteína quinasa activada por mitógenos (MAP), inmunidad innata y respuesta proinflamatoria $(43,44)$

La UPR consta de tres ramas mediadas por tres sensores de señalización transmembrana del RE: PERK (proteína quinasa ER similar a PKR), IRE1 (inositol que requiere la enzima 1), y ATF6 (Factor de transcripción activador 6) (44). En condiciones normales, estas tres proteínas de señalización están unidas por la proteína 78 regulada por glucosa (GRP78/ $\mathrm{BiP})$, una proteína chaperona, que mantiene la UPR en un estado inactivo, pero al acumularse proteínas mal plegadas en el RE, GRP78 se libera de los tres sensores activándolos (45). Luego, se une a las proteínas mal plegadas para regular su plegamiento y disminuye la traducción de proteínas, mientras que los tres sensores activados desencadenan una compleja cascada de transducción de señales (42-45).

Se ha encontrado que células infectadas con SARS-CoV, o que sobre-expresan la subunidad S2, presentan altos niveles de expresión de los genes GRP94 y GRP78, lo que sugiere que este virus tiene un efecto directo sobre la UPR (Figura 2B) $(46,47)$. También se ha detectado una significativa fosforilación de elF2 $\alpha$, PKR y PERK en células infectadas con SARS-CoV quien, además, emplea una estrategia para contrarrestar los efectos antivirales de PKR y cuya inhibición no afecta la replicación viral $(47,48)$. Aunque el mecanismo de la apoptosis inducida por UPR es bastante limitado, parece que el efecto de la rama PERK es generalmente protector y que esta rama regula la inmunidad innata suprimiendo la señalización del interferón tipo I (IFN $\alpha / \beta)(48,49)$. 
Los resultados publicados sugieren que SARS-CoV, y posiblemente SARS-CoV-2, usen la rama PERK como un mecanismo para atenuar la inmunidad innata en la célula huésped, promoviendo la supervivencia celular. A pesar que la infección por el $\beta$-coronavirus $\mathrm{MHV}$ induce corte y empalme de XBP1, SARS-CoV no ha demostrado experimentalmente tener efecto sobre XBP1, por lo que se ha propuesto que las proteínas virales del SARS-CoV y posiblemente de SARS-CoV-2, sean antagonista de la activación IRE1-XBP1 (42,50).

El papel de la rama ATF6 en la infección por CoV no se ha investigado en profundidad. Sin embargo, se ha comprobado que las proteínas de espiga no son capaces de activar esta rama, aunque la proteína accesoria de 8ab de SARS-CoV y la proteína ORF8 de SARS-CoV-2 inducen la proteólisis de ATF6 $(42,51,52)$.

Una vez ocurrida la proteólisis, el dominio bZIP de ATF6-p50 se transloca al núcleo y fomenta la producción de chaperonas del RE, como GRP78 y, de esta forma mejora la capacidad de plegamiento de proteínas para reducir el estrés $(42,43)$, Cuando este mecanismo falla, las señales mediadas por la rama ATF6 contribuyen a la apoptosis, muy probablemente por la activación de CHOP y la supresión de Mcl-1 $(53,54)$.

Se ha demostrado que los agonistas de ACE2 contribuyen a la reducción del estrés del RE. Por ello se ha propuesto que la ocupación de ACE2 por la glicoproteína $S$ puede intensificar el estrés del RE mediante la inhibición de la señalización de ACE2, y siendo ésta una de las causas de la fibrosis pulmonar observada en COVID-19 $(44,55,56)$.

Autofagia y SARS-CoV-2. La autofagia es un mecanismo de control durante la infección viral que favorece la degradación mediada por lisosomas de ácidos nucleicos, lípidos, proteínas y orgánulos defectuosos, así como componentes de microorganismos invasores. Sin embargo, también se ha descrito que algunas infecciones virales pueden verse beneficiadas por este mecanismo que podría facilitar el ensamblaje de proteínas replicasas, promoviendo la replicación viral $(13,57)$. La inducción de autofagia en células hospedadoras durante una infección viral puede darse como una respuesta al estrés del RE durante la replicación, ya que se ha descrito que la UPR y la autofagia están interconectadas de forma que la autofagia es un mecanismo de respuesta celular que se genera luego de la activación de la UPR, funcionando como un mecanismo de control (57).

La autofagia se inicia mediante la formación del fagóforo, una estructura de doble membrana que envuelve al material que será degradado y lo secuestra dentro de un autofagosoma. El autofagosoma maduro se fusiona con un lisosoma para generar un autolisosoma donde finalmente el material se degradará. Se ha sugerido un efecto inhibidor de SARSCoV y MERS-CoV sobre el proceso de autofagia, aunque se desconoce si este efecto es necesario para la replicación viral. Las proteínas Nsp6, p4b y p5 han demostrado tener poder de limitación de los autofagosomas, siendo la proteína Nsp6 común para otros betacoronavirus (13, 21,57). Además, se ha encontrado que la Nsp14 favorece la degradación lisosomal de IFN tipo I, ORF3a previene la fusión autofagosoma-lisosoma, y ORF7a interfiere con la acidificación del autofagosoma que logra fusionarse a lisosoma (Figura 2C) (57).

La Nsp6 es una proteína transmembrana implicada en la formación de DMV durante la infección por SARS-CoV. La sobre-expresión de Nsp6 de IBV (gammacoronavirus), MHV o SARS-CoV (betacoronavirus) activa la formación de autofagosomas del RE, pero estos autofagosomas tienen diámetros pequeños, indicando que esta proteína restringe la expansión de los mismos (13).

Reflexiones finales. Hasta finales de octubre 2021 se han reportado 244 millones de personas infectadas y 4,55 millones de casos de muertes en todo el mundo por la pandemia por COVID-19. Se han desarrollado vacunas que previenen las formas graves de la enfermedad pero se siguen produciendo casos de infección, y se generan nuevas variantes resistentes a la respuesta inmunitaria. Por ello, habrá que entender la fisiopatología de la enfermedad y los mecanismos de interacción entre el virus y las células huésped. Las rutas de estrés celular han sido bien caracterizadas y constituyen una gran herramienta para comprender la patogenia y biología del SARS-CoV-2 e identificar blancos terapéuticos.

Aunque se han demostrado algunas interacciones de proteínas virales de $\mathrm{CoV}$ con componentes de las rutas de estrés, se debe continuar la investigación experimental, para comprender las diferencias y similitudes entre los componentes proteicos que ya han sido identificados en esta familia viral, sus diversas acciones en las células huésped y cuáles son los mecanismos de respuesta celular más eficientes tanto para la progresión de la infección, como para su contención.

Financiamiento. Este trabajo fue financiado por el Instituto Venezolano de Investigaciones Científicas (IVIC), proyecto \#1107: Mecanismos de patogénesis viral, y por el Ministerio del Poder Popular de Ciencia y Tecnología, proyecto: Desarrollo de capacidades para el estudio y control del coronavirus causante de la COVID-19.

\section{REFERENCIAS BIBLIOGRÁFICAS}

1. Zhu N, Zhang D, Wang W, Li X, Yang B, Song J, et al. A Novel Coronavirus from Patients with Pneumonia in China, 2019. N Engl J Med 2020; 382:727-733.

2. Chan JF, Kok KH, Zhu Z, Chu H, To KK, Yuan S, Yuen KY. Genomic characterization of the 2019 novel human-pathogenic coronavirus isolated from a patient with atypical pneumonia after visiting Wuhan. Emerg Microbes Infect. 2020; 28:9(1):221-236.

3. Chen Y, Liu Q, Guo D. Emerging coronaviruses: Genome structure, replication, and pathogenesis. J Med Virol 2020; 92(4): 418-423.

4. Perlman S, Netland J. Coronaviruses post-SARS: Update on replication and pathogenesis. Nat Rev Microbiol 2009; 7(6):439450.

\section{Salus Revista de la Facultad de Giencias de la Salud. Universidad de Garahoho. Septiembre/Diciembre 2021 Vol. 25 ํo 3}


5. Gaut JR, Hendershot LM. The modification and assembly of proteins in the endoplasmic reticulum. Curr Opin Cell Biol. 1993; 5(4):589-595.

6. Hetz C, Martinon F, Rodriguez D, Glimcher LH. The unfolded protein response: integrating stress signals through the stress sensor IRE1a. Physiol Rev. 2011;91(4):1219-1243.

7. Minakshi R, Padhan K, Rani M, Khan N, Ahmad F, Jameel S. The SARS Coronavirus 3 a protein causes endoplasmic reticulum stress and induces ligand-independent downregulation of the type 1 interferon receptor. PLoS One. 2009; 17; 4(12):e8342. https://doi.org/10.1371/journal.pone.0008342.

8. Chan SW. The unfolded protein response in virus infections. Front Microbiol 2014; 30; 5:518.

9. Malhotra JD, Kaufman RJ. Endoplasmic reticulum stress and oxidative stress: A vicious cycle or a double-edged sword? Antioxid Redox Signal 2007; 9(12):2277-2293.

10. Walter P, Ron D. The unfolded protein response: From stress pathway to homeostatic regulation. Science 2011; 334(6059):1081-1086.

11. Ghavami S, Sharma P, Yeganeh B, Ojo OO, Jha A, Mutawe MM, et al. Airway mesenchymal cell death by mevalonate cascade inhibition: integration of autophagy, unfolded protein response and apoptosis focusing on $\mathrm{Bcl} 2$ family proteins. Biochim Biophys Acta. 2014;1843(7):1259-1271.

12. Ghavami S, Yeganeh B, Zeki AA, Shojaei S, Kenyon NJ, Ott $S$, et al. Autophagy and the unfolded protein response promote profibrotic effects of TGF- $\beta 1$ in human lung fibroblasts. Am J Physiol Lung Cell Mol Physiol. 2018 1; 314(3):L493-L504. https://doi.org/10.1152/ajplung.00372.2017.

13. Cottam EM, Maier HJ, Manifava M, Vaux LC, ChandraSchoenfelder P, Gerner W, et al. Coronavirus nsp6 proteins generate autophagosomes from the endoplasmic reticulum via an omegasome intermediate. Autophagy 2011; 7(11): 13351347.

14. Zhao Z, Lu K, Mao B, Liu S, Trilling M, Huang A, et al. The interplay between emerging human coronavirus infections and autophagy. Emerg Microbes Infect 2021; 10(1):196-205

15. Zhong J, Guo D, Chen CB, Wang W, Schuster M, Loibner H, Penninger JM, Scholey JW, Kassiri Z, Oudit GY. Prevention of angiotensin II-mediated renal oxidative stress, inflammation, and fibrosis by angiotensin-converting enzyme 2 . Hypertension. 2011;57(2):314-322.

16. Kim SM, Kim YG, Jeong KH, Lee SH, Lee TW, Ihm CG, Moon JY. Angiotensin II-induced mitochondrial Nox4 is a major endogenous source of oxidative stress in kidney tubular cells. PLoS One. 2012; 7(7):e39739. doi: 10.1371/journal. pone.0039739.

17. Suhail S, Zajac J, Fossum C, Lowater H, McCracken C, Severson $\mathrm{N}$, et al. Role of oxidative stress on SARS-CoV (SARS) and SARS-CoV-2 (COVID-19) infection: a review. Protein J 2020; 39(6): 644-656.

18. V'kovski P, Kratzel A, Steiner S, Stalder H, Thiel V. Coronavirus biology and replication: implications for SARS-CoV-2 Nat Rev Microbiol 2021;19, 155-170

19. Wang MY, Zhao R, Gao LJ, Gao XF, Wang DP, Cao JM. SARSCoV-2: structure, biology, and structure-based therapeutics development. Front Cell Infect Microbiol. 2020; 10:587269. https://doi.org/10.3389/fcimb.2020.587269.

20. Glebov OO. Understanding SARS-CoV-2 endocytosis for COVID-19 drug repurposing. FEBS J 2020; 287(17): 36643671.
21. Santerre, M., Arjona, S.P., Allen, C.N. et al. Why do SARSCoV-2 NSPs rush to the ER?. J Neurol 2021;268: 2013-2022.

22. Fung TS, Liu DX. Human Coronavirus: host-pathogen interaction. Annu Rev Microbiol 2019; 73:529-557.

23. Sies $H$. Oxidative stress: from basic research to clinical application. Am J Med. 1991; 91(3C): 31S-38S.

24. Liguori I, Russo G, Curcio F, Bulli G, Aran L, Della-Morte D, et al. Oxidative stress, aging, and diseases. Clin Interv Aging. 2018; 13:757-772.

25. Zhang Z, Rong L, Li YP. Flaviviridae Viruses and oxidative stress: implications for viral pathogenesis. Oxid Med Cell Longev. 2019; 2019:1409582. https://doi.org/10.1155/2019/1409582.

26. Roy J, Galano JM, Durand T, Le Guennec JY, Lee JC. Physiological role of reactive oxygen species as promoters of natural defenses. FASEB J 2017; 31(9):3729-3745.

27. Reshi ML, Su YC, Hong JR. RNA Viruses: ROS-mediated cell death. Int J Cell Biol. 2014; 2014:467452. https://doi.org/ $10.1155 / 2014 / 467452$.

28. Checconi P, De Angelis M, Marcocci ME, Fraternale A, Magnani M, Palamara AT, Nencioni L. Redox-Modulating agents in the treatment of viral infections. Int J Mol Sci. 2020; 21(11):4084. https://doi.org/10.3390/ijms21114084.

29. Beck MA, Handy J, Levander OA. The role of oxidative stress in viral infections. Ann N Y Acad Sci. 2000; 917:906-912.

30. Lin CW, Lin KH, Hsieh TH, Shiu SY, Li JY. Severe acute respiratory syndrome coronavirus $3 \mathrm{C}$-like protease-induced apoptosis. FEMS Immunol Med Microbiol. 2006; 46(3): 375-380.

31. Kanzawa N, Nishigaki K, Hayashi T, Ishii Y, Furukawa S, Niiro $A$, et al. Augmentation of chemokine production by severe acute respiratory syndrome coronavirus $3 a / X 1$ and $7 a / X 4$ proteins through NF-kappaB activation. FEBS Lett. 2006; 580(30): 68076812.

32. Chan CM, Tsoi H, Chan WM, Zhai S, Wong CO, Yao X, Chan WY, Tsui SK, Chan HY. The ion channel activity of the SARScoronavirus 3a protein is linked to its pro-apoptotic function. Int J Biochem Cell Biol. 2009; 41(11): 2232-2239.

33. Delgado-Roche L, Mesta F. Oxidative stress as key player in Severe Acute Respiratory Syndrome Coronavirus (SARS-CoV) infection. Arch Med Res 2020; 51(5):384-387.

34. Issa E, Merhi G, Panossian B, Salloum T, Tokajian S. SARSCoV-2 and ORF3a: nonsynonymous mutations, functional domains, and viral pathogenesis. mSystems. 2020; 5(3):e0026620. https://doi.org/10.1128/mSystems.00266-20.

35. Lingappan K. NF-KB in oxidative stress. Curr Opin Toxicol 2018; 7:81-86.

36. Zhang L, Wei L, Jiang D, Wang J, Cong X, Fei R. SARS-CoV nucleocapsid protein induced apoptosis of COS-1 mediated by the mitochondrial pathway. Artif Cells Blood Substit Immobil Biotechnol. 2007; 35(2): 237-253.

37. Padhan K, Minakshi R, Towheed MAB, Jameel S. Severe acute respiratory syndrome coronavirus $3 a$ protein activates the mitochondrial death pathway through p38 MAP kinase activation. J Gen Virol. 2008; 89(Pt 8):1960-1969.

38. Battagello DS, Dragunas G, Klein MO, Ayub ALP, Velloso FJ, Correa RG. Unpuzzling COVID-19: tissue-related signaling pathways associated with SARS-CoV-2 infection and transmission. Clin Sci (Lond). 2020; 134(16): 2137-2160.

39. Bartoszewski R, Dabrowski M, Jakiela B, Matalon S, Harrod KS, Sanak $\mathrm{M}$, et al. SARS-CoV-2 may regulate cellular responses through depletion of specific host miRNAs. Am J Physiol Lung Cell Mol Physiol 2020; 319(3): L444-L455. 
40. Paladino L, Vitale AM, Caruso Bavisotto C, Conway de Macario E, Cappello F, Macario AJL, Gammazza AM. The role of molecular chaperones in virus infection and implications for understanding and treating COVID-19. J Clin Med. 2020; 9(11): 3518. https://doi.org/10.3390/jcm9113518.

41. Fukushi M, Yoshinaka Y, Matsuoka Y, Hatakeyama S, Ishizaka Y, Kirikae T, Sasazuki T, Miyoshi-Akiyama T. Monitoring of $S$ protein maturation in the endoplasmic reticulum by calnexin is important for the infectivity of severe acute respiratory syndrome coronavirus. J Virol. 2012; 86(21):11745-11753

42. Fung TS, Liu DX. Coronavirus infection, ER stress, apoptosis and innate immunity. Front Microbiol. 2014; 5:296. https://doi. org/10.3389/fmicb.2014.00296.

43. Khomari F, Nabi-Afjadi M, Yarahmadi S. Eskandari H, Bahreini E. Effects of cell proteostasis network on the survival of SARSCoV-2. Biol Proced Online 2021; 23(1):8 https://doi.org/10.1186/ s12575-021-00145-9.

44. Ibrahim IM, Abdelmalek DH, Elfiky AA. GRP78: A cell's response to stress. Life Sci. 2019; 226:156-163.

45. Yeung YS, Yip CW, Hon CC, Chow KY, Ma IC, Zeng F, Leung FC. Transcriptional profiling of Vero E6 cells over-expressing SARS-CoV S2 subunit: insights on viral regulation of apoptosis and proliferation. Virology. 2008; 71(1): 32-43.

46. Fung TS, Huang M, Liu DX. Coronavirus-induced ER stress response and its involvement in regulation of coronavirushost interactions. Virus Res 2014; 194:110-123. https://doi. org/10.1016/j.virusres.2014.09.016.

47. Krähling V, Stein DA, Spiegel M, Weber F, Mühlberger E. Severe acute respiratory syndrome coronavirus triggers apoptosis via protein kinase $\mathrm{R}$ but is resistant to its antiviral activity. $\mathrm{J}$ Virol 2009; 83(5):2298-2309.

48. DeDiego ML, Nieto-Torres JL, Jiménez-Guardeño JM, ReglaNava JA, Alvarez E, Oliveros JC, Zhao J, Fett C, Perlman S, Enjuanes L. Severe acute respiratory syndrome coronavirus envelope protein regulates cell stress response and apoptosis. PLoS Pathog. 2011;7(10):e1002315. https://doi.org/10.1371/ journal.ppat.1002315.
49. Sung SC, Chao CY, Jeng KS, Yang JY, Lai MM. The 8ab protein of SARS-CoV is a luminal ER membrane-associated protein and induces the activation of ATF6. Virology 2009; 387(2):402-413.

50. Rashid F, Dzakah EE, Wang H, Tang S. The ORF8 protein of SARS-CoV-2 induced endoplasmic reticulum stress and mediated immune evasion by antagonizing production of interferon beta. Virus Res. 2021; 296:198350. https://doi. org/10.1016/j.virusres.2021.198350.

51. Gotoh T, Oyadomari S, Mori K, Mori M. Nitric oxide-induced apoptosis in RAW 264.7 macrophages is mediated by endoplasmic reticulum stress pathway involving ATF6 and CHOP. J Biol Chem 2002; 277(14):12343-12350.

52. Morishima N, Nakanishi K, Nakano A. Activating transcription factor-6 (ATF6) mediates apoptosis with reduction of myeloid cell leukemia sequence $1(\mathrm{Mcl}-1)$ protein via induction of WW domain binding protein 1. J Biol Chem. 2011; 286(40): 35227 35235 .

53. Uhal BD, Li X, Piasecki CC, Molina-Molina M. Angiotensin signalling in pulmonary fibrosis. International $\mathrm{J}$ Biochem Cell Biol 2012;44(3):465-468

54. Cao X, Lu XM, Tuo X, Liu JY, Zhang YC, Song LN, Cheng ZQ, Yang JK, Xin Z. Angiotensin-converting enzyme 2 regulates endoplasmic reticulum stress and mitochondrial function to preserve skeletal muscle lipid metabolism. Lipids Health Dis 2019; 18(1):207. https://doi.org/10.1186/s12944-019-1145-x.

55. Aman Y, Schmauck-Medina T, Hansen M, Morimoto RI, Simon AK, Bjedov I, et al. Autophagy in healthy aging and disease. Nat Aging 2021;1(8): 634-650.

56. Shojaei S, Suresh M, Klionsky DJ, Labouta HI, Ghavami S. Autophagy and SARS-CoV-2 infection: a possible smart targeting of the autophagy pathway. Virulence 2020;11(1):805810.

57. Hayn M, Hirschenberger M, Koepke L, Nchioua R, Straub $\mathrm{JH}$, Klute $\mathrm{S}$ et al. Systematic functional analysis of SARSCoV-2 proteins uncovers viral innate immune antagonists and remaining vulnerabilities. Cell Rep 2021; 35(7):109126. https:// doi.org/10.1016/j.celrep.2021.109126. 